Supplement of Atmos. Chem. Phys., 21, 4319-4337, 2021

https://doi.org/10.5194/acp-21-4319-2021-supplement

(C) Author(s) 2021. CC BY 4.0 License.

(c) (1)

Atmospheric
Chemistry
and Physics

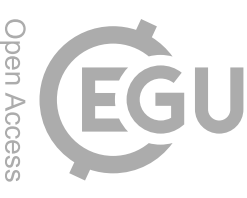

Supplement of

\title{
A revised mineral dust emission scheme in GEOS-Chem: improvements in dust simulations over China
}

\section{Rong Tian et al.}

Correspondence to: Xiaoyan Ma (xma@nuist.edu.cn)

The copyright of individual parts of the supplement might differ from the article licence. 


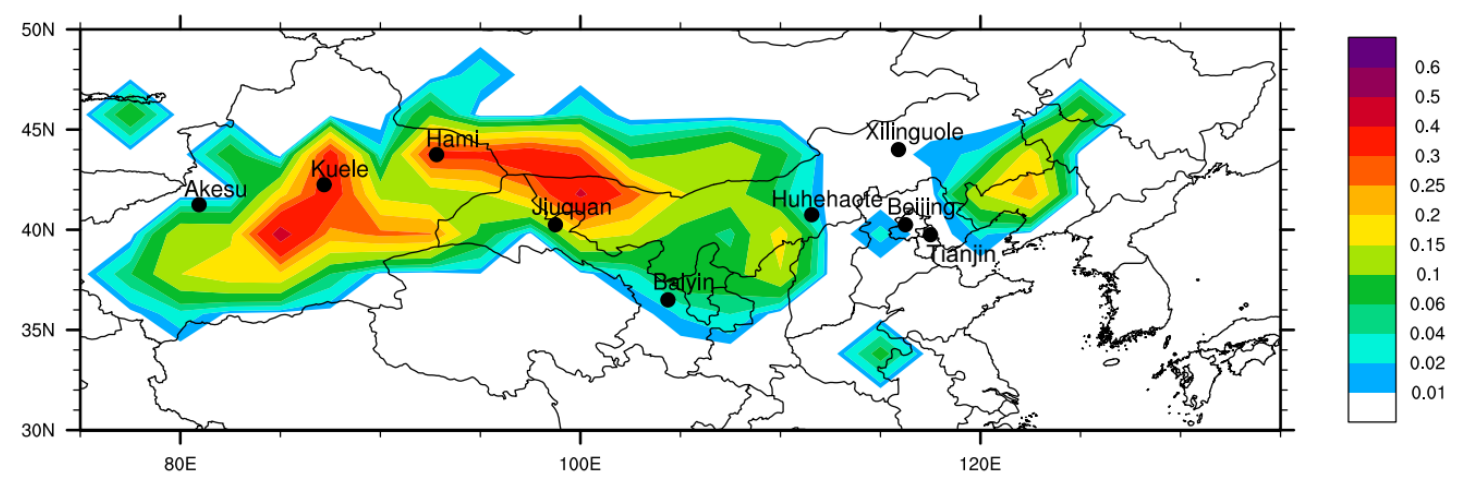

Fig S1. The erodibility factor S from Ginoux et al. (2001) used in this study. The black dots represent the locations of the nine selected sites in this study.
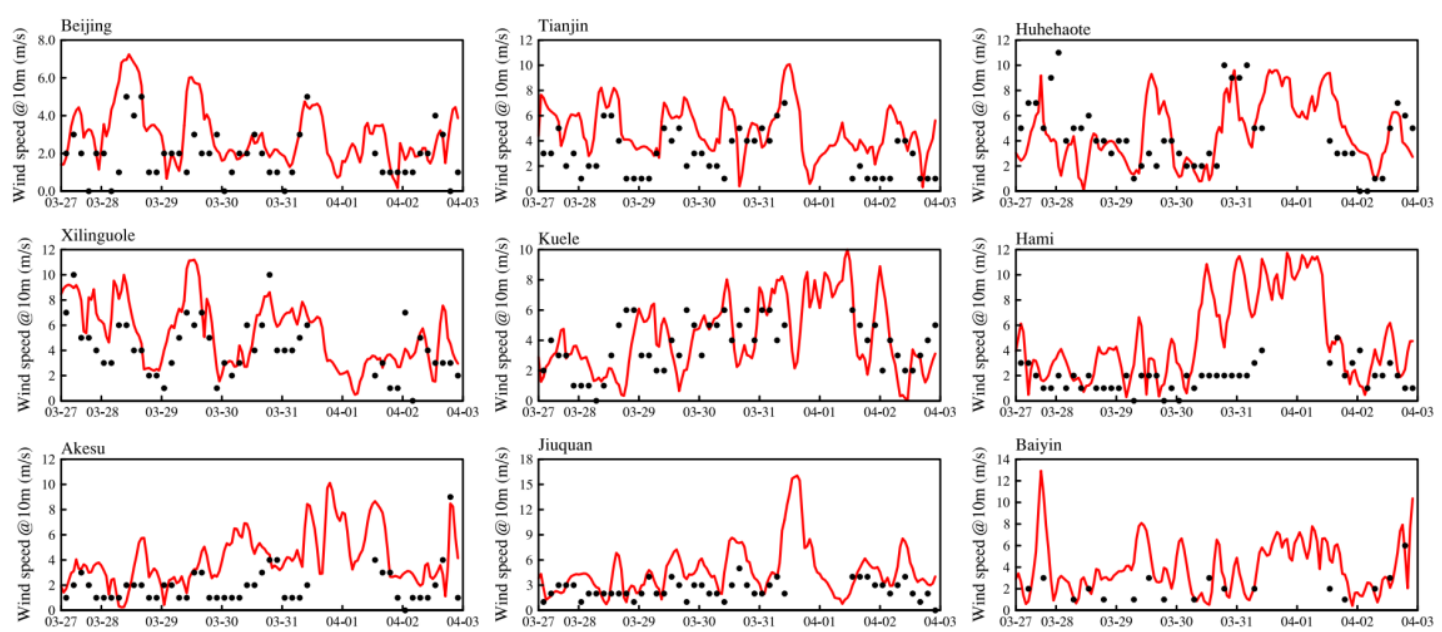

Fig S2. Time series of the simulated (lines) and observed (dots) $10 \mathrm{~m}$ wind speed, $10 \mathrm{~m}$ wind speed at selected sites during study period.
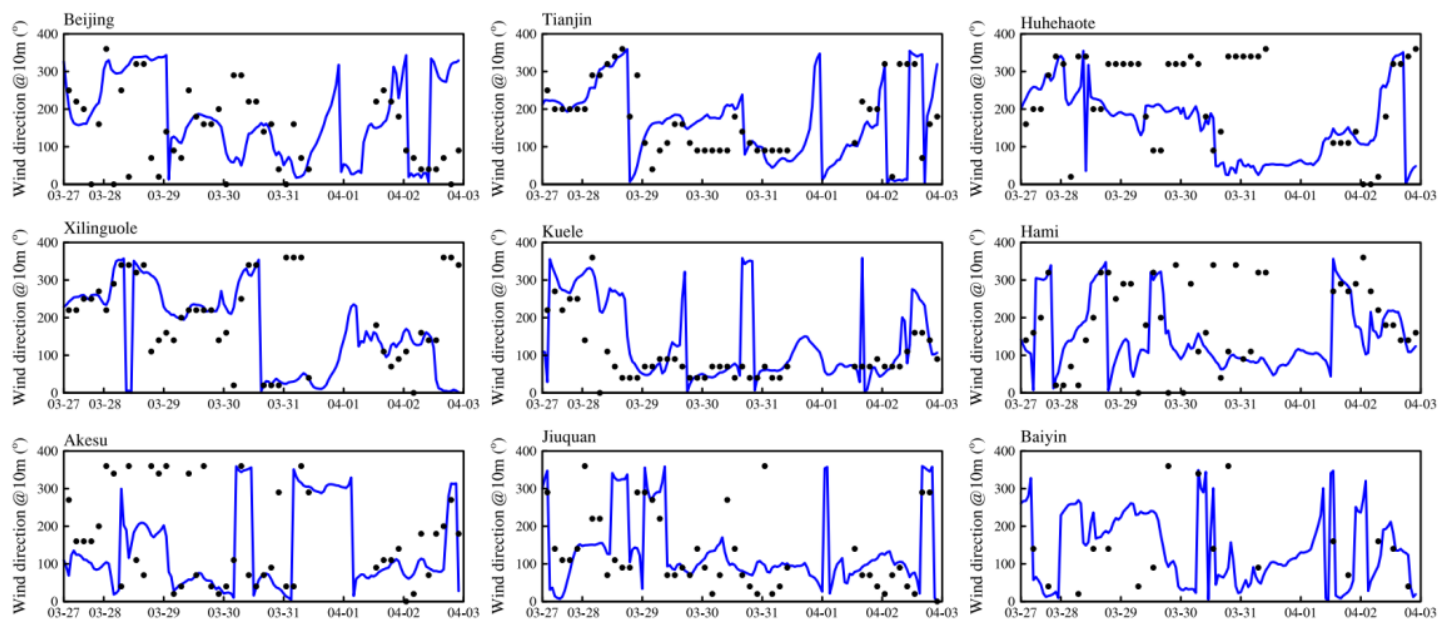

Fig S3. Time series of the simulated (lines) and observed (dots) $10 \mathrm{~m}$ wind direction at selected sites during study period. 

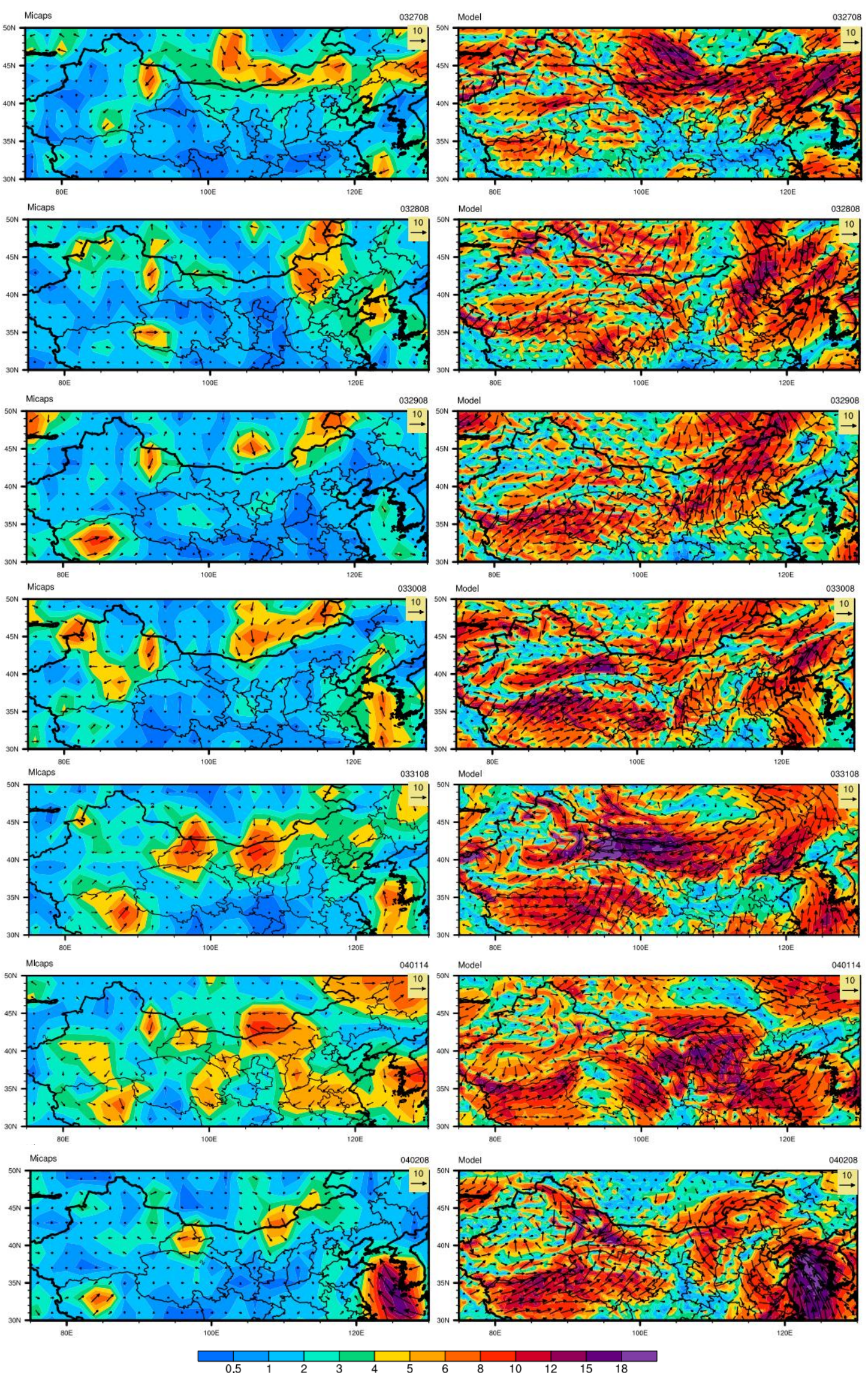

Fig S4. Comparisons of averaged surface wind field between the model data (right panel) and 
observations (left panel) from Micaps during the study period. 